\title{
Elucidating Surface Structure with Action Spectroscopy
}

\author{
Yun Liu," Zongfang Wu," Matthias Naschitzki, Sandy Gewinner, Wieland Schöllkopf, Xiaoke Li," \\ Joachim Paier,* Joachim Sauer, Helmut Kuhlenbeck,* and Hans-Joachim Freund
}

Cite This: J. Am. Chem. Soc. 2020, 142, 2665-2671

Read Online

ABSTRACT: Surface Action Spectroscopy, a vibrational spectroscopy method developed in recent years at the Fritz Haber Institute is employed for structure determination of clean and $\mathrm{H}_{2} \mathrm{O}$-dosed (111) magnetite surfaces. Surface structural information is revealed by using the microscopic surface vibrations as a fingerprint of the surface structure. Such vibrations involve just the topmost atomic layers, and therefore the structural information is truly surface related. Our results strongly support the view that regular $\mathrm{Fe}_{3} \mathrm{O}_{4}(111) / \mathrm{Pt}(111)$ is terminated by the so-called $\mathrm{Fe}_{\text {tet } 1}$ termination, that the biphase termination of $\mathrm{Fe}_{3} \mathrm{O}_{4}(111) / \mathrm{Pt}(111)$ consists of $\mathrm{FeO}$ and $\mathrm{Fe}_{3} \mathrm{O}_{4}(111)$ terminated areas, and we show that the method can differentiate

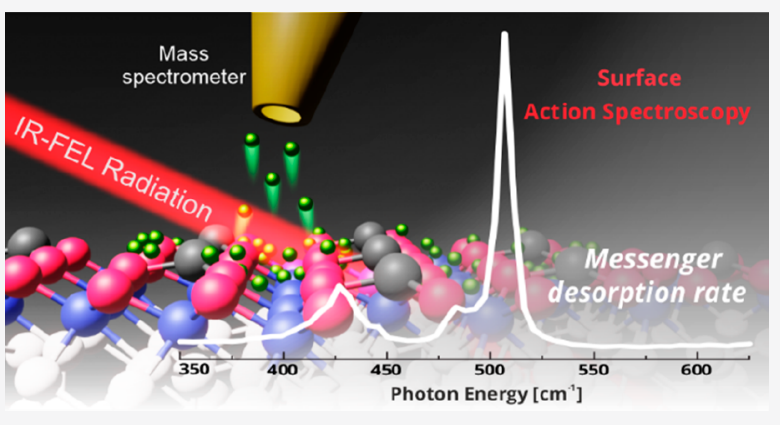
between different water structures in $\mathrm{H}_{2} \mathrm{O}$-derived adsorbate layers on $\mathrm{Fe}_{3} \mathrm{O}_{4}(111) / \mathrm{Pt}(111)$. With this, we conclude that the method is a capable new member in the set of techniques providing crucial information to elucidate surface structures. The method does not rely on translational symmetry and can therefore also be applied to systems which are not well ordered. Even an application to rough surfaces is possible.

\section{INTRODUCTION}

Structure-reactivity relationships are important descriptors for the catalytic activity of surfaces. The experimental determination of such a relationship requires reactivity studies but also an experimental determination of the surface structure on a microscopic scale. There is a number of surface-sensitive methods to reveal the atomic structure of surfaces; most of them may be classified either as scanning probe or as diffraction technique.

Vibrational methods are capable of providing useful information for elucidating surface structures, for instance via IRAS (Infrared Reflection Absorption Spectroscopy) with probe molecules. ${ }^{1}$ However, the latter information is somewhat indirect and a vibrational spectroscopy method providing direct access to surface properties would be desirable.

In recent years a new vibrational method, Surface Action Spectroscopy (SAS) as a tool to measure surface vibrational spectra, has been developed at the Fritz Haber Institute. ${ }^{2,3}$ This method is based on a concept that is now often applied in gas phase infrared spectroscopy if the sample's density is extremely low and absorption measurements cannot be performed due to this: ${ }^{4-6}$ molecules or clusters in a molecular beam are exposed to inert messenger species (for example rare gas atoms) which attach to them with a weak bond at low temperature. These messenger-decorated aggregates are then exposed to intense infrared radiation, often coming from a free electron laser (FEL). If the photon energy is suitable for excitation of one of the aggregate's vibrational modes, then the energy absorbed from the infrared beam may break the bonds between the messengers and the aggregates (this is the "action" in the term "action spectroscopy"), such that a flow of messenger atoms may be detected with a mass spectrometer. Recording the messenger desorption rate as a function of the photon energy produces a vibrational spectrum. ${ }^{4-6}$ We have applied such a procedure to messengers adsorbed on surfaces and demonstrated its usefulness in surface vibrational spectroscopy.

Here we use this method to measure vibrational spectra of different iron oxide layers in the range of about 300 to 700 $\mathrm{cm}^{-1}$, where a number of microscopic optical surface vibrations is situated. Such surface vibrations usually involve only a few surface layers of a sample and therefore the information contained in the vibrational spectra is truly surface-related. HREELS (high-resolution electron energy loss spectroscopy), HAS (helium atom scattering), and IRAS can also be used for such measurements, but there are issues. ${ }^{2,7}$ The spectral resolution of HREELS is only moderate. A commonly used type of spectrometer (Ibach design ${ }^{8}$ ) has a resolution of 4 $\mathrm{cm}^{-1}$ at best, with the real-life operation resolution being about $10 \mathrm{~cm}^{-1}$ in favorite examples, but rather often significantly lower. Also, in HREELS intense Fuchs-Kliewer polariton losses and combination losses may hide part of the desired spectral

Received: December 6, 2019

Published: January 22, 2020 
information. Off-specular measurement may partially alleviate this issue, but this leads to low intensities and may force consideration of surface phonon dispersion in the calculation of the vibrational spectrum. IRAS spectra are produced by dividing two spectra-the spectrum of the sample under investigation is divided by a reference spectrum, which would ideally be a spectrum of a sample with the same bulk absorption spectrum as the sample under investigation, but without surface absorption features since this would introduce spurious features into the IRAS spectrum. Such a reference sample does not usually exist, which severely limits the suitability of IRAS for the spectroscopy of surface vibrations. In the case of HAS, the energy is limited to below $\sim 480 \mathrm{~cm}^{-1}$, and the surfaces have to be very flat on a microscopic scale. SAS does not suffer from such issues; a spectrum can be measured in just a few minutes. The method does not rely on reflected intensities which has the consequence that it can also be applied to nonflat surfaces.

Common diffraction-based methods for structure determination at the atomic level are IV-LEED (intensity voltage lowenergy electron diffraction) and GIXRD (grazing incidence Xray diffraction), which are successfully used for surface structure determination since many years. In both cases wellordered surfaces with well-defined diffraction spots are required. This is not the case for SAS since it is not based on diffraction, which is a relevant advantage with respect to the diffraction-based methods. Scanning probe techniques such as STM (scanning tunneling microscopy) and AFM (atomic force microscopy) are also suitable for surface structure determination, but they are not directly element sensitive and information about deeper layers is not revealed.

Iron oxides have been intensively studied for several decades $^{9-13}$ since they are important compounds used in catalysis, magnetism, electrochemistry, and biomedical applications. The surface structure of magnetite $\left(\mathrm{Fe}_{3} \mathrm{O}_{4}\right)(111)$ has been under discussion for a long time. Along (111), the $\mathrm{Fe}_{3} \mathrm{O}_{4}$ bulk lattice consists of six different planes denoted as $\mathrm{Fe}_{\text {tet } 1}, \mathrm{O}_{1}$, $\mathrm{Fe}_{\text {oct } 1}, \mathrm{O}_{2}, \mathrm{Fe}_{\text {tet2 } 2}$, and $\mathrm{Fe}_{\text {oct2 }}{ }^{9-11}$ Two of these layers, $\mathrm{Fe}_{\text {tet1 }}$ and $\mathrm{Fe}_{\mathrm{oct} 2}$, have been discussed as terminating layers of the (111) surface. $\mathrm{Fe}_{\text {tet } 1}$ layers in the bulk consist of a $1 / 4 \mathrm{ML}$ of $\mathrm{Fe}_{\mathrm{tet}}{ }^{3+}$ ions and $\mathrm{Fe}_{\text {oct2 }}$ bulk layers are made up of $1 / 4 \mathrm{ML}$ of $\mathrm{Fe}_{\text {tet }}{ }^{3+}$ and 1/4 ML of $\mathrm{Fe}_{\text {oct }}{ }^{2+}$. Models of the $\mathrm{Fe}_{\text {tet1 }}$ and $\mathrm{Fe}_{\text {oct2 }}$ terminations are shown in the Supporting Information, SI, Figure S1. The surface unit cells of these two terminations are identical, and therefore a LEED pattern-based differentiation between them is not possible. IV-LEED studies are in favor of the $\mathrm{Fe}_{\text {tet1 }}$ termination, ${ }^{14-17}$ even though surface inhomogeneities and defects somewhat hampered the studies. STM studies of $\mathrm{Fe}_{3} \mathrm{O}_{4}(111)$ thin films on $\mathrm{Pt}(111)^{16,18}$ are mostly in favor of the $\mathrm{Fe}_{\text {tet } 1}$ termination, while studies of magnetite single crystal surfaces also find evidence of the $\mathrm{Fe}_{\text {oct2 }}$ termination under reducing preparation conditions. ${ }^{19,20}$ IRAS studies with a CO adsorbate led to mixed results, partially favoring the $\mathrm{Fe}_{\text {tet }}$, and partially the $\mathrm{Fe}_{\text {oct } 2}$ termination. ${ }^{21-23}$

We have used SAS to obtain surface vibrational spectra for different iron oxide thin films and present evidence that the biphase $\mathrm{Fe}_{3} \mathrm{O}_{4}(111)$ does contain an FeO-type oxide at the surface. Via a comparison with vibrational spectra computed using density functional theory (DFT) for model surface terminations we show that $\mathrm{Fe}_{3} \mathrm{O}_{4}(111)$ is terminated with $\mathrm{Fe}_{\text {tet } 1}$, and that the method can differentiate between different water-derived species on $\mathrm{Fe}_{3} \mathrm{O}_{4}(111)$. The DFT results confirm that most of the vibrational information stems from the outermost three atom layers, which means that the vibrational spectrum is a selective fingerprint of the surface structure.

\section{EXPERIMENTAL SECTION}

Experimental Details. The iron oxides thin films on a $\mathrm{Pt}(111)$ surface were prepared following published recipes. ${ }^{9,13,24-28} \mathrm{FeO}(111)$ layers with a thickness of one $\mathrm{O}-\mathrm{Fe}$ double layer were prepared by deposition of $\mathrm{Fe}$ at $300 \mathrm{~K}$ followed by annealing at $1000 \mathrm{~K}$ in $1 \times 10^{-6}$ mbar of $\mathrm{O}_{2} \cdot{ }^{9,13}$ In the following we use the term ML such that $1 \mathrm{ML}$ contains the same amount of iron as one complete $\mathrm{FeO}(111)$ layer on $\mathrm{Pt}(111) . \mathrm{Fe}_{3} \mathrm{O}_{4}(111)$ and biphase $\mathrm{Fe}_{2} \mathrm{O}_{3}(0001)$ films on $\mathrm{Pt}(111)$ were prepared in two steps: in the first step a 1-2 ML thick $\mathrm{FeO}(111)$ film was prepared on $\mathrm{Pt}(111)$. Following this, the $\mathrm{Fe}_{3} \mathrm{O}_{4}(111)$ and biphase $\mathrm{Fe}_{2} \mathrm{O}_{3}(0001)$ layers were prepared by several cycles of deposition of $10 \mathrm{ML}$ of Fe at $300 \mathrm{~K}$ with subsequent oxidation. The oxidation was performed at $870-900 \mathrm{~K}$ in $1 \times 10^{-6}$ mbar of $\mathrm{O}_{2}$ for $\mathrm{Fe}_{3} \mathrm{O}_{4}(111)$ and at $870 \mathrm{~K}$ in $3 \times 10^{-5} \mathrm{mbar}$ of $\mathrm{O}_{2}$ for biphase $\mathrm{Fe}_{2} \mathrm{O}_{3}(0001)$. ${ }^{29}$ For $\mathrm{Fe}_{3} \mathrm{O}_{4}(111)$ cooling in UHV after oxidation was employed to avoid the growth of oxygen-rich steps on the surface. ${ }^{15,22}$ The biphase $\mathrm{Fe}_{3} \mathrm{O}_{4}(111)$ studies were performed with reduced $\mathrm{Fe}_{3} \mathrm{O}_{4}(111)$ samples-these were prepared by deposition of $1 \AA$ of $\mathrm{Fe}$ at the SAS measurement temperature $(5-10 \mathrm{~K})$ followed by annealing at $800 \mathrm{~K}$ in UHV. Before each SAS measurement the samples were annealed at $800 \mathrm{~K}$ in UHV to remove contaminations.

The SAS experimental setup is schematically shown in Figure 1. A surface is decorated with weakly bound messengers (rare gas atoms or

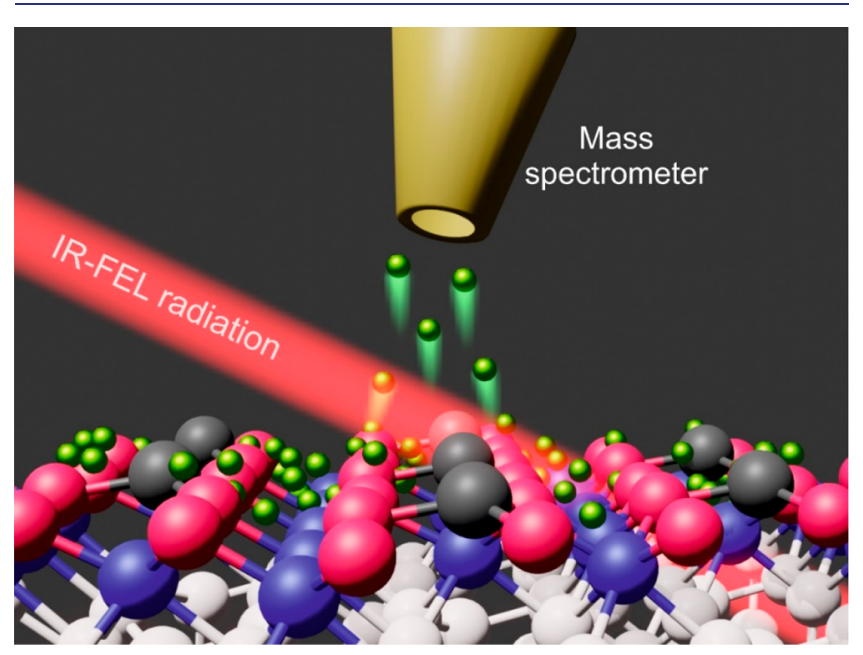

Figure 1. Schematic sketch of the SAS setup. Blue, red, gray, and white balls are substrate atoms, and the small green balls are messengers.

hydrogen molecules) at low temperature and exposed to an infrared beam, which comes from the free electron laser of the Fritz Haber Institute in the present case. Vibrations excited at the sample surface may lead to messenger desorption as an indicator of the vibrational excitation. Therefore, the messenger desorption rate as measured with a mass spectrometer represents a vibrational spectrum of the surface. Details of the experimental setup can be found in previous work. ${ }^{2,3}$ All SAS spectra shown here were obtained with a $\mathrm{HD}$ molecular messenger gas. The spectral resolution depends somewhat on the energy and was around $4 \mathrm{~cm}^{-1}$ for the experiments discussed here.

Computational Details. The electronic and ionic structures were calculated using the projector-augmented-wave (PAW) method, which is implemented in the Vienna ab initio simulation package (VASP). ${ }^{30-32}$ Plane wave kinetic energies of up to $800 \mathrm{eV}$ were employed. To describe exchange-correlation effects, the Perdew, Burke, and Ernzerhof (PBE) generalized-gradient approximation (GGA) with spin-polarization was used. ${ }^{33}$ For Fe $3 d$ on-site Coulomb 

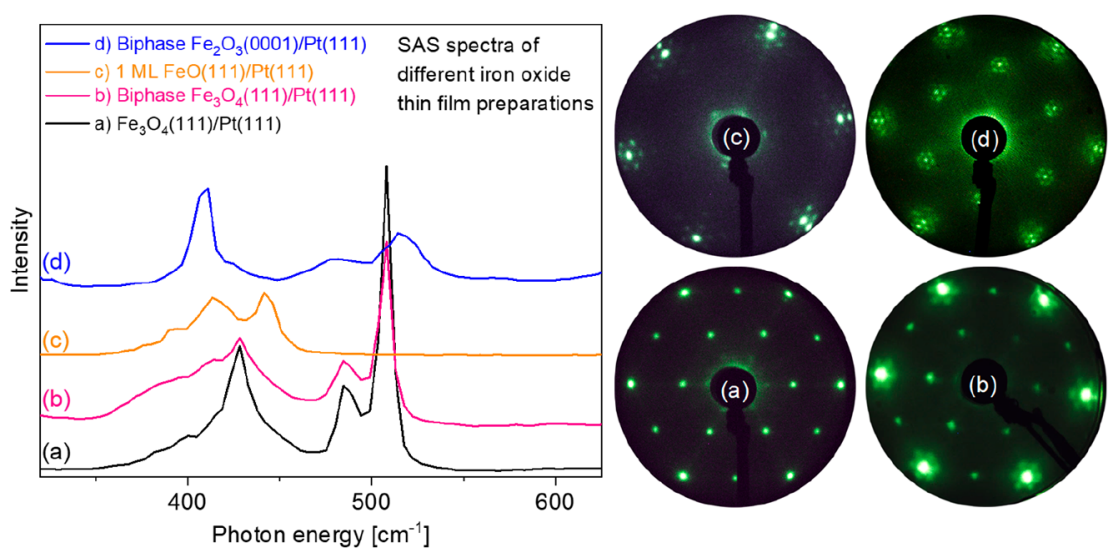

Figure 2. Surface action spectra of different iron oxide films on $\mathrm{Pt}(111)$. The right panel displays LEED images for the samples $\left[(\mathrm{a}),(\mathrm{c}),(\mathrm{d}): E_{\text {electron }}\right.$ $\left.=66 \mathrm{eV} ;(\mathrm{b}): E_{\text {electron }}=54 \mathrm{eV}\right]$.

correlation effects, an effective Hubbard-type $\mathrm{U}$ parameter of $3.8 \mathrm{eV}$ was added as in previous work. ${ }^{22,34}$

We use PAW pseudopotentials released with VASP 5.2 to describe the electron-ion interaction. The pseudopotential for the Fe has 14 electrons (Fe pv: $[\mathrm{Mg}] 3 \mathrm{p}^{6} 3 \mathrm{~d}^{7} 4 \mathrm{~s}^{1}$ as a ground state configuration) while there are 6 electrons $\left([\mathrm{He}] 2 s^{2} 2 p^{4}\right)$ for $\mathrm{O}$, and one valence electron for $\mathrm{H}$. Electronic and ionic optimizations were performed using a break criterion of $10^{-5} \mathrm{eV}$, and a maximal atom force of 0.02 $\mathrm{eV} / \AA$ was applied. For the self-consistent field (SCF) loops, the Gaussian smearing method with a width of $0.1 \mathrm{eV}$ was employed.

Concerning the structures used in this work, the slab model includes 12 atomic layers to calculate $\mathrm{Fe}_{3} \mathrm{O}_{4}(111)$ surfaces as reported before. For the $\mathrm{Fe}_{3} \mathrm{O}_{4}(111)-(1 \times 1)$ primitive cell, a Monkhorst-Pack $\mathrm{k}$ mesh of $5 \times 5 \times 1$ was employed. For the frequency calculation, central differences for the force derivative with atomic displacements of $\pm 0.015 \AA$ were used to calculate the (partial) Hessian matrix. The topmost three layers were free to move to get the energies of the surface vibrations. To test the convergence of the energy, utilization of four layers of clean $\mathrm{Fe}_{3} \mathrm{O}_{4}(111)$ surface with $\mathrm{Fe}_{\text {tet } 1}$ termination was calculated. As a result of $\mathrm{PBE}+\mathrm{U}$, the lattice constant of $\mathrm{Fe}_{3} \mathrm{O}_{4}$ bulk is $8.508 \AA$, which slightly overestimates the experimental value of 8.396 $\AA$, rendering computed vibrations softer. To compare with the observed surface vibrations, computed wavenumbers are scaled by a factor of 1.0655 (see SI Table S1). Regarding water adsorption structures, we use a $\mathrm{Fe}_{3} \mathrm{O}_{4}(111)-(1 \times 1)$ surface unit cell adsorbing a single $\mathrm{OH}$, one, and two $\mathrm{H}_{2} \mathrm{O}$ molecules.

\section{RESULTS AND DISCUSSION}

We have studied a number of different iron oxide films (SAS spectra are shown in Figure 2) to explore the applicability of SAS for surface structure determination. It is clear from Figure 2 that SAS spectra of the microscopic surface vibrations are fingerprints of the surface structure, which means that we have access to the surface structure using such data.

One monolayer thick $\mathrm{FeO}(111)$ films on $\mathrm{Pt}(111)$ consist of a hexagonal $\mathrm{Fe}-\mathrm{O}$ bilayer structure with oxygen termination. ${ }^{9,28}$ The characteristic Moire pattern observed with LEED (see Figure 2) is due to the lattice mismatch between $\mathrm{FeO}(111)$ and $\mathrm{Pt}(111) .^{9,25,28,35}$ Correspondingly, the STM images reveal a superlattice with long lattice vectors. The Fe$O$ bond length in the Moire superlattice depends on the position above the $\mathrm{Pt}(111)$ substrate, ${ }^{35-37}$ leading to a wide distribution of vibrational energies ranging from 380 to 450 $\mathrm{cm}^{-1}$ in the SAS spectrum (Figure 2c). This structured broad feature resembles a structure at about $20 \mathrm{~cm}^{-1}$ lower energy in a surface phonon spectrum calculated by Spiridis et al. for 1 $\mathrm{ML} \mathrm{FeO}(111)$ on $\mathrm{Pt}(111)$. $^{38}$
Figure $2 \mathrm{~b}$ shows that the spectrum of biphase $\mathrm{Fe}_{3} \mathrm{O}_{4}(111)$ (produced by iron deposition as described in the Experimental Section) is slightly different from the spectrum of regular $\mathrm{Fe}_{3} \mathrm{O}_{4}(111)$ (Figure 2a). The intense peak at above $500 \mathrm{~cm}^{-1}$ is somewhat weaker and the feature at $\sim 425 \mathrm{~cm}^{-1}$ is wider, with part of the additional intensity reminding of the $\mathrm{FeO}(111)$ feature in a similar energy range (Figure 2c), indicating that a $\mathrm{FeO}(111)$-type structure contributes to the spectrum in panel $b$. The corresponding LEED pattern exhibits Moiré spots (see Figure 2), and the STM image shows a welldefined Moiré structure on parts of the image area ${ }^{9,16}$ (see SI Figure S2). A LEED pattern similar to that shown in Figure 2 for reduced $\mathrm{Fe}_{3} \mathrm{O}_{4}(111)$ has been observed by Condon et al. ${ }^{39}$ who attributed it to a superlattice of $\mathrm{Fe}_{3} \mathrm{O}_{4}(111)$ and $\mathrm{Fe}_{1-x} \mathrm{O}(111)$ patches and invoked the term "biphase" for this structure. The conclusion that FeO-related structures show up at the surface after deposition of iron was also drawn by Spiridis et al. ${ }^{40}$ The spectral features in the SAS spectra of biphase $\mathrm{Fe}_{3} \mathrm{O}_{4}(111)$ and $\mathrm{FeO}(111)$ in the range below $\sim 470$ $\mathrm{cm}^{-1}$ (see Figure 2) are similar but not identical, which means that the extra intensity in the spectrum of biphase $\mathrm{Fe}_{3} \mathrm{O}_{4}(111)$ is not due (at least not fully) to dewetting of the layer, which might expose $\mathrm{FeO}(111) / \mathrm{Pt}(111)$, but also to something different such as an $\mathrm{FeO}(111)$-type layer on $\mathrm{Fe}_{3} \mathrm{O}_{4}(111)$, as also proposed by Spiridis et al. ${ }^{39,40}$ This conclusion is supported by indications of Moire spots in the LEED image also around those $\mathrm{Fe}_{3} \mathrm{O}_{4}(111)$ spots which are not near to the $\mathrm{FeO}(111) / \mathrm{Pt}(111)$ spots. We note that even in Figure $2 \mathrm{a}$, the spectrum of "regular" $\mathrm{Fe}_{3} \mathrm{O}_{4}(111)$, weak indications of $\mathrm{FeO}(111)$ are visible in the left and right shoulders of the peak at $\sim 425 \mathrm{~cm}^{-1}$. Consequently, weak Moiré spots are visible in the LEED pattern. The spectrum of biphase $\mathrm{Fe}_{2} \mathrm{O}_{3}(0001)$ will not be discussed in detail. It is just shown as another example that the SAS spectra are surface-specific.

It is clear from this discussion that the vibrational surface modes are characteristic for the arrangement of atoms at the surface. Therefore, it should be possible to use SAS spectra for the elucidation of the surface structure via comparison with computed vibrational data for model structures. This approach was tested for the spectrum of clean $\mathrm{Fe}_{3} \mathrm{O}_{4}(111)$.

To this end we have computed surface vibrational energies for the $\mathrm{Fe}_{\text {tet } 1}$ and $\mathrm{Fe}_{\text {oct2 }}$ terminations of $\mathrm{Fe}_{3} \mathrm{O}_{4}(111)$. The computed energies of the most intense modes are compared with the experimental data in Figure 3. We note that only the topmost three layers of the oxide were considered in the 


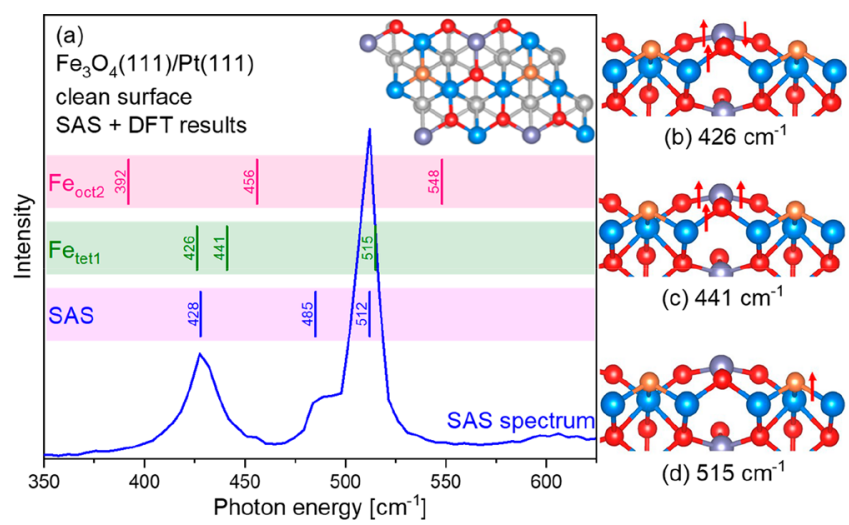

Figure 3. (a) Graphical comparison of computed vibrational energies for the $\mathrm{Fe}_{\text {tet1 }}$ and $\mathrm{Fe}_{\text {oct2 }}$ terminations of $\mathrm{Fe}_{3} \mathrm{O}_{4}(111)$ with SAS peak energies. The experimental SAS spectrum is shown as a blue curve. The inset shows a model of the $\mathrm{Fe}_{\text {tet1 }}$ terminated clean $\mathrm{Fe}_{3} \mathrm{O}_{4}(111)$ surface (top view). (b),(c),(d): Graphical illustration of the three most intense $\mathrm{Fe}_{\text {tet } 1}$ surface vibration modes (side view). Color code: $\mathrm{Fe}_{\text {tet } 1}$ and $\mathrm{Fe}_{\mathrm{tet} 2}$, violet balls; $\mathrm{Fe}_{\text {oct } 1}$ and $\mathrm{Fe}_{\text {oct2 }}$, light blue balls; and orange and red balls represent two inequivalent surface oxygen atoms, denoted as $\mathrm{O}_{b}$ (orange) and $\mathrm{O}_{\mathrm{a}}$ (red).

computation of the vibrational energies. Consideration of a fourth layer did not change the numbers significantly (see SI Table S2), which demonstrates that the information is very surface specific. It is clear from Figure 3 that the vibrational energies computed for the $\mathrm{Fe}_{\text {tet1 }}$ terminated surface (olive row in Figure 3) fit well to the measured vibrational energies: the 428 and $512 \mathrm{~cm}^{-1}$ SAS peaks are quite well reproduced by the 426 and $515 \mathrm{~cm}^{-1}$ computed modes, the experimental peak at $485 \mathrm{~cm}^{-1}$ is due to water traces, as discussed below, and the computed mode at $441 \mathrm{~cm}^{-1}$ is probably hidden in the wide peak centered at $428 \mathrm{~cm}^{-1}$.

The agreement is much worse for the $\mathrm{Fe}_{\text {oct2 }}$ termination (pink row). Thus, we conclude that $\mathrm{Fe}_{3} \mathrm{O}_{4}(111)$ is terminated by $\mathrm{Fe}_{\text {tet } 1}$ under the given experimental conditions, as also reported in most other studies, ${ }^{22,26}$ but at variance with a recent structural study involving a CO adsorbate. ${ }^{23}$ Panels (b), (c), and (d) in Figure 3 graphically represent the normal modes of the three $\mathrm{Fe}_{\text {tet1 }}$ surface vibrations. The top layer in the drawings is the $\mathrm{Fe}_{\text {tet1 }}$ layer, below is an oxygen layer consisting of two inequivalent types of oxygen atoms, $\mathrm{O}_{\mathrm{a}}$ and $\mathrm{O}_{\mathrm{b}}{ }^{34}$ and the third layer is an iron layer, $\mathrm{Fe}_{\mathrm{oct} 1}$. The strongest peak (SAS: $512 \mathrm{~cm}^{-1}$, DFT: $515 \mathrm{~cm}^{-1}$ ) is the out-of-plane stretching mode of $\mathrm{O}_{\mathrm{b}}$ atoms relative to the $\mathrm{Fe}_{\text {oct1 }}$ subsurface layer (Figure $3 \mathrm{~d}$ ) while the other two vibrational modes involve asymmetric (Figure $3 b$ ) and symmetric (Figure 3c) displacements of $\mathrm{O}_{a}$ and $\mathrm{O}_{b}$ atoms relative to the $\mathrm{Fe}_{\text {tet1 }}$ and $\mathrm{Fe}_{\text {oct1 }}$ layers, respectively.

The experimentally observed peak at $485 \mathrm{~cm}^{-1}$ is missing in the set of calculated surface vibrational energies of both, the $\mathrm{Fe}_{\text {tet1 }}$ and $\mathrm{Fe}_{\text {oct2 }}$ terminations (Figure 3). Since this peak is apparently not a vibration of the regular $\mathrm{Fe}_{\text {tet } 1}$ surface it might stem from a contamination. A common contamination of $\mathrm{Fe}_{3} \mathrm{O}_{4}(111)$, water, has been studied in detail in recent papers. ${ }^{26,41-44}$ STM images (Figure S3) indicate that waterderived species were also present on the sample used here. Therefore, it was near at hand to assume that the peak at 485 $\mathrm{cm}^{-1}$ results from the presence of a water-derived species at the surface.
The effect of a water adsorbate on the surface vibrational spectrum of $\mathrm{Fe}_{3} \mathrm{O}_{4}(111)$ was investigated with SAS and DFT. Figure $4 \mathrm{a}$ compares an SAS spectrum of a surface after water

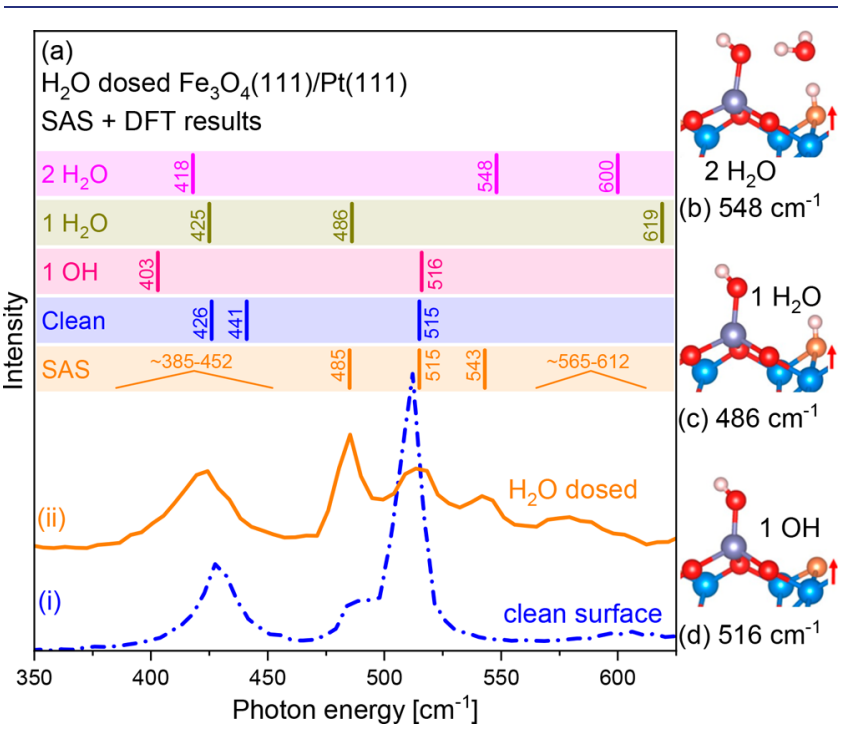

Figure 4. (a) SAS spectra of clean $\mathrm{Fe}_{3} \mathrm{O}_{4}$ (111) (dash dotted, blue) and of a water multilayer on $\mathrm{Fe}_{3} \mathrm{O}_{4}(111)$ flashed to $293 \mathrm{~K}$ after water dosage at $\sim 255 \mathrm{~K}$ (solid, orange). The orange row labeled "SAS" lists the experimental values derived from the orange SAS spectrum, the blue row labeled "Clean" repeats the computed results for tet1terminated clean $\mathrm{Fe}_{3} \mathrm{O}_{4}(111)$ (see Figure 3), while the other rows refer to DFT results for one $\mathrm{OH}$ group per unit cell (pink), a partially dissociated water molecule per unit cell (dark yellow), and two water molecules per unit cell, one of them partially dissociated (magenta) on $\mathrm{Fe}_{\text {tet1 }}$ terminated $\mathrm{Fe}_{3} \mathrm{O}_{4}(111)$. (b), (c), (d): Sketches of the waterderived structures on $\mathrm{Fe}_{\text {tet } 1}$ terminated $\mathrm{Fe}_{3} \mathrm{O}_{4}(111)$ considered in the DFT calculations. The numbers refer to the energies of the most intense vibrations of the respective structures, which are all derived from the most intense vibration of the clean $\mathrm{Fe}_{3} \mathrm{O}_{4}(111)$ surface at $512 \mathrm{~cm}^{-1}$.

dosage with a spectrum of a clean surface, and lists vibrational energies computed with DFT for $\mathrm{Fe}_{\text {tet } 1}$ terminated $\mathrm{Fe}_{3} \mathrm{O}_{4}(111)$ with different water-derived adsorbate layers. Recent studies of the $\mathrm{H}_{2} \mathrm{O}-\mathrm{Fe}_{3} \mathrm{O}_{4}(111)$ interaction $^{26,41}$ indicate that water in contact with the $\mathrm{Fe}_{\text {tet } 1}$ terminated surface dissociates, giving rise to different structures depending on coverage. TPD (temperature-programmed desorption) data reveal a complex phase structure and LEED shows that the structures exhibit long-range ordering. ${ }^{26,41}$ The structures considered here (a hydroxyl group, a dissociated water molecule, and a dissociated water molecule plus a less affected water molecule coordinated via hydrogen bonds) are inspired by structures considered in those recent studies. ${ }^{26,41}$ They are sketched in Figure 4, panels $(b-d)$, together with the energies of the modes which are correlated with the most intense one in the spectrum of the clean surface (at $512 \mathrm{~cm}^{-1}$ ). It is clear that the peak at 485 $\mathrm{cm}^{-1}$ in the "clean-surface" spectrum is best assigned to the structure with the partially dissociated water molecule as shown in Figure 4c, while the peak at $543 \mathrm{~cm}^{-1}$ can be attributed to the structure with two water molecules per unit cell (Figure $4 b$ ). There is no conclusive evidence for the presence of the structure with one hydroxyl group per unit cell (Figure 4d): the computed mode at $403 \mathrm{~cm}^{-1}$ is experimentally not detectable and the computed mode at $516 \mathrm{~cm}^{-1}$ is very near to the clean surface mode, which is 
because the hydrogen atom is not coordinated to a surface atom with a high vibrational amplitude. This is different for the other structures where the energy shift is larger. Another effect of the water-derived adsorbate layer is a shift of the peak at 428 $\mathrm{cm}^{-1}$ in the spectrum of the clean surface to a lower energy which may be attributed to the lower energies of the respective computed modes for the adsorbate covered surface. The wide feature between $\sim 565$ and $612 \mathrm{~cm}^{-1}$ in the experimental spectrum (Figure 4a(ii)) does probably consist of several vibrational transitions. One of them may be assigned to the structure with two water molecules (Figure $4 \mathrm{~b}$, at $600 \mathrm{~cm}^{-1}$ ) but there are surely also other peaks, which may be attributed to water dimers, water aggregates, adsorption on defects, ${ }^{41}$ or $\mathrm{H}_{2} \mathrm{O}$-related structures with a higher coverage. ${ }^{45}$ Therefore, most of the features in the experimental spectrum may be attributed to the structures sketched in Figure 4, panels $(b-d)$, which supports the assignments made in recent publications. $^{26,41}$

As we have shown, the spectrum of surface vibrational modes is a fingerprint of the surface structure and therefore computations may help to elucidate it. This does also apply to adsorbate structures. In the present case (water-derived adsorbates) the result is indirect since the observed bands are not directly adsorbate vibrations but modified substrate vibrations. This may also be seen as an advantage since the modification of these vibrations by the adsorbate is an indicator of the adsorbate's effect on the substrate surface.

Atomic level structural information about a surface or an adsorbate/substrate complex is important for essentially all processes involving the interaction of molecules/atoms with surfaces such as heterogeneous catalysis, corrosion, sensing, wear, etc. A relevant aspect of the vibrational SAS approach is that translational symmetry is not required, which means that structure determination is possible also for surfaces without diffraction spots, where methods such as IV-LEED and GIXRD encounter difficulties. Thus, SAS is very suitable to study complex water-oxide interfaces, in which water agglomerates show only locally ordered structures. ${ }^{46,47}$ In the discussed case of water on $\mathrm{Fe}_{3} \mathrm{O}_{4}(111)$ we were able to reveal the structures of different coexisting types of adsorbate complexes. In case that very many types of adsorbate structure are present at the surface it may still be possible to identify the most abundant structures, i.e., those which dominate the spectra.

We note that in the present case the surface vibrational energies of $\mathrm{Fe}_{3} \mathrm{O}_{4}(111)$ depend sensitively on details of the adsorbate layer (see Figure 4), indicating that this type of spectroscopy may be highly sensitive to minor differences in an adsorbate layer, possibly more sensitive than the study of the $\mathrm{O}-\mathrm{H}$ vibrations would be.

\section{CONCLUSIONS}

In conclusion, we have acquired SAS spectra of different iron oxide layers on $\mathrm{Pt}(111)$, and $\mathrm{Fe}_{3} \mathrm{O}_{4}(111)$ covered with waterderived species, with the goal of elucidating the suitability of SAS for surface structural characterization with the help of computations. The surface modes are highly sensitive to the structural arrangement of the surface atoms, and therefore the surface vibrations represent a fingerprint of the surface structure. SAS may be used to reveal this information. In agreement with preceding publications we could show that $\mathrm{Fe}_{3} \mathrm{O}_{4}(111)$ is terminated with an $\mathrm{Fe}_{\text {tet1 }}$ layer, which is contaminated with a small amount of dissociatively adsorbed $\mathrm{H}_{2} \mathrm{O}$ under usual UHV conditions. In addition to this we were able to present spectroscopic evidence that biphase $\mathrm{Fe}_{3} \mathrm{O}_{4}(111)$ consists of regular $\mathrm{Fe}_{3} \mathrm{O}_{4}(111)$ coexisting with $\mathrm{FeO}(111)$, as also commonly discussed in the literature. With the example of water on $\mathrm{Fe}_{3} \mathrm{O}_{4}(111)$ we have shown that SAS may also be used to differentiate with high selectivity between different adsorbate structures. The two most relevant aspects of SAS are probably that it can be applied to rough surfaces and that it does not require the presence of long-range ordered structures, such as IV-LEED and GIXRD, which makes weakly ordered or even unordered systems suitable for full or partial structure determination as long as repeating structure elements are available.

\section{ASSOCIATED CONTENT}

\section{SI Supporting Information}

The Supporting Information is available free of charge at https://pubs.acs.org/doi/10.1021/jacs.9b13164.

Bulk phonons of the $\mathrm{Fe}_{3} \mathrm{O}_{4}$ cubic phase; calculated vibrational energies of the $\mathrm{Fe}_{\text {tet1 }}$ terminated $\mathrm{Fe}_{3} \mathrm{O}_{4}(111)$ surface; ball and stick models of the $\mathrm{Fe}_{\text {tet1 }}$ and $\mathrm{Fe}_{\text {oct2 }}$ surfaces; STM images of $\mathrm{FeO}(111) / \mathrm{Pt}(111)$, biphase $\mathrm{Fe}_{3} \mathrm{O}_{4}(111)$, and regular $\mathrm{Fe}_{3} \mathrm{O}_{4}(111)$; and graphical representations of the vibrational modes of $\mathrm{OH}, \mathrm{H}_{2} \mathrm{O}$, and $2 \mathrm{H}_{2} \mathrm{O}$ on $\mathrm{Fe}_{\text {tet1 }}$ terminated $\mathrm{Fe}_{3} \mathrm{O}_{4}(111)$ (PDF)

\section{AUTHOR INFORMATION}

\section{Corresponding Authors}

Joachim Paier - Institut für Chemie, Humboldt Universität zu Berlin, 10099 Berlin, Germany; 이이이.org/0000-00016085-2211; Email: joachim.paier@chemie.hu-berlin.de

Helmut Kuhlenbeck - Fritz-Haber-Institut der Max-PlanckGesellschaft, 14195 Berlin, Germany; 이이.org/0000-00016384-8883; Email: kuhlenbeck@fhi-berlin.mpg.de

\section{Authors}

Yun Liu - Fritz-Haber-Institut der Max-Planck-Gesellschaft, 14195 Berlin, Germany; () orcid.org/0000-0001-9630-7610

Zongfang Wu - Fritz-Haber-Institut der Max-PlanckGesellschaft, 14195 Berlin, Germany

Matthias Naschitzki - Fritz-Haber-Institut der Max-PlanckGesellschaft, 14195 Berlin, Germany

Sandy Gewinner - Fritz-Haber-Institut der Max-PlanckGesellschaft, 14195 Berlin, Germany

Wieland Schöllkopf - Fritz-Haber-Institut der Max-PlanckGesellschaft, 14195 Berlin, Germany; (ㅇ orcid.org/0000-00030564-203X

Xiaoke Li - Institut für Chemie, Humboldt Universität zu Berlin, 10099 Berlin, Germany

Joachim Sauer - Institut für Chemie, Humboldt Universität zu Berlin, 10099 Berlin, Germany; 이이.org/0000-00016798-6212

Hans-Joachim Freund - Fritz-Haber-Institut der Max-PlanckGesellschaft, 14195 Berlin, Germany; 이이.org/0000-00015188-852X

Complete contact information is available at:

https://pubs.acs.org/10.1021/jacs.9b13164

\section{Author Contributions}

"These authors contributed equally to this work.

\section{Notes}

The authors declare no competing financial interest. 


\section{ACKNOWLEDGMENTS}

Y.L. and Z.W. thank the Alexander von Humboldt Foundation $(\mathrm{AvH})$ for supporting them with an $\mathrm{AvH}$ research grant. We thank the Deutsche Forschungsgemeinschaft for funds through the Collaborative Research Center (CRC) 1109 "Understanding of Metal Oxide/Water Systems at the Molecular Scale. Structural Evolution, Interfaces, and Dissolutions". The Fonds der Chemischen Industrie is gratefully acknowledged for financial support. J.P. and X.L. acknowledge financial support by the Deutsche Forschungsgemeinschaft (DFG) within grant 426182295 and HPC resources provided by the Norddeutsche Verbund für Hoch- und Höchstleistungsrechnen (HLRN).

\section{REFERENCES}

(1) Wang, Y.; Wöll, C. IR Spectroscopic Investigations of Chemical and Photochemical Reactions on Metal Oxides: Bridging the Materials Gap. Chem. Soc. Rev. 2017, 46, 1875-1932.

(2) Wu, Z.; Płucienik, A.; Feiten, F. E.; Naschitzki, M.; Wachsmann, W.; Gewinner, S.; Schöllkopf, W.; Staemmler, V.; Kuhlenbeck, H.; Freund, H.-J. Vibrational Action Spectroscopy of Solids: New SurfaceSensitive Technique. Phys. Rev. Lett. 2017, 119 (13), 136101.

(3) Wu, Z.; Płucienik, A.; Liu, Y.; Naschitzki, M.; Wachsmann, W.; Gewinner, S.; Schöllkopf, W.; Kuhlenbeck, H.; Freund, H.-J. Surface Action Spectroscopy with Rare Gas Messenger Atoms. Rev. Sci. Instrum. 2018, 89 (8), 083107.

(4) Asmis, K. R. Structure Characterization of Metal Oxide Clusters by Vibrational Spectroscopy: Possibilities and Prospects. Phys. Chem. Chem. Phys. 2012, 14 (26), 9270-9281.

(5) Fielicke, A.; Meijer, G.; von Helden, G. Infrared Spectroscopy of Niobium Oxide Cluster Cations in a Molecular Beam: Identifying the Cluster Structures. J. Am. Chem. Soc. 2003, 125 (12), 3659-3667.

(6) Gruene, P.; Rayner, D. M.; Redlich, B.; van der Meer, A. F. G.; Lyon, J. T.; Meijer, G.; Fielicke, A. Structures of Neutral $A_{4}, A u_{19}$, and $\mathrm{Au}_{20}$ Clusters in the Gas Phase. Science 2008, 321 (5889), 674676.

(7) Surface Phonons; Kress, W., Wette, F. W., Eds.; Springer Series in Surface Sciences; Springer: Berlin/Heidelberg, 1991.

(8) Ibach, H. Electron Energy Loss Spectroscopy with Resolution below $1 \mathrm{meV}$. J. Electron Spectrosc. Relat. Phenom. 1993, 64-65, 819823.

(9) Weiss, W.; Ranke, W. Surface Chemistry and Catalysis on WellDefined Epitaxial Iron-Oxide Layers. Prog. Surf. Sci. 2002, 70 (1), 1151.

(10) Kuhlenbeck, H.; Shaikhutdinov, S.; Freund, H.-J. Well-Ordered Transition Metal Oxide Layers in Model Catalysis - A Series of Case Studies. Chem. Rev. 2013, 113 (6), 3986-4034.

(11) Parkinson, G. S. Iron Oxide Surfaces. Surf. Sci. Rep. 2016, 71 (1), 272-365.

(12) Qiu, H.; Staemmler, V.; Kuhlenbeck, H.; Bauer, E.; Freund, H.J. Weak Thermal Reduction of Biphase $\mathrm{Fe}_{2} \mathrm{O}_{3}(0001)$ Films Grown on $\mathrm{Pt}(111)$ : Sub-Surface $\mathrm{Fe}^{2+}$ Formation. Surf. Sci. 2015, 641, 30-36.

(13) Lewandowski, M.; Groot, I. M. N.; Qin, Z.-H.; Ossowski, T.; Pabisiak, T.; Kiejna, A.; Pavlovska, A.; Shaikhutdinov, S.; Freund, H.J.; Bauer, E. Nanoscale Patterns on Polar Oxide Surfaces. Chem. Mater. 2016, 28 (20), 7433-7443.

(14) Weiss, W.; Barbieri, A.; Van Hove, M. A.; Somorjai, G. A. Surface Structure Determination of an Oxide Film Grown on a Foreign Substrate: $\mathrm{Fe}_{3} \mathrm{O}_{4}$ Multilayer on $\mathrm{Pt}(111)$ Identified by Low Energy Electron Diffraction. Phys. Rev. Lett. 1993, 71 (12), 18481851.

(15) Sala, A.; Marchetto, H.; Qin, Z.-H.; Shaikhutdinov, S.; Schmidt, Th.; Freund, H.-J. Defects and Inhomogeneities in $\mathrm{Fe}_{3} \mathrm{O}_{4}$ Thin Film Growth on Pt(111). Phys. Rev. B: Condens. Matter Mater. Phys. 2012, 86 (15), 155430.

(16) Shaikhutdinov, Sh. K.; Ritter, M.; Wang, X.-G.; Over, H.; Weiss, W. Defect Structures on Epitaxial $\mathrm{Fe}_{3} \mathrm{O}_{4}$ Films. Phys. Rev. B: Condens. Matter Mater. Phys. 1999, 60 (15), 11062-11069.
(17) Ritter, M.; Weiss, W. $\mathrm{Fe}_{3} \mathrm{O}_{4}(111)$ Surface Structure Determined by LEED Crystallography. Surf. Sci. 1999, 432 (1), $81-94$.

(18) Weiss, W.; Ritter, M. Metal Oxide Heteroepitaxy: StranskiKrastanov Growth for Iron Oxides on Pt(111). Phys. Rev. B: Condens. Matter Mater. Phys. 1999, 59 (7), 5201-5213.

(19) Shimizu, T. K.; Jung, J.; Kato, H. S.; Kim, Y.; Kawai, M. Termination and Verwey Transition of the (111) Surface of Magnetite Studied by Scanning Tunneling Microscopy and FirstPrinciples Calculations. Phys. Rev. B: Condens. Matter Mater. Phys. 2010, 81 (23), 235429.

(20) Lennie, A. R.; Condon, N. G.; Leibsle, F. M.; Murray, P. W.; Thornton, G.; Vaughan, D. J. Structures of $\mathrm{Fe}_{3} \mathrm{O}_{4}(111)$ Surfaces Observed by Scanning Tunneling Microscopy. Phys. Rev. B: Condens. Matter Mater. Phys. 1996, 53 (15), 10244-10253.

(21) Lemire, C.; Meyer, R.; Henrich, V. E.; Shaikhutdinov, Sh.; Freund, H.-J. The Surface Structure of $\mathrm{Fe}_{3} \mathrm{O}_{4}(111)$ Films as Studied by CO Adsorption. Surf. Sci. 2004, 572 (1), 103-114.

(22) Li, X.; Paier, J.; Sauer, J.; Mirabella, F.; Zaki, E.; Ivars-Barceló, F.; Shaikhutdinov, S.; Freund, H.-J. Surface Termination of $\mathrm{Fe}_{3} \mathrm{O}_{4}(111)$ Films Studied by $\mathrm{CO}$ Adsorption Revisited. J. Phys. Chem. B 2018, 122 (2), 527-533.

(23) Schöttner, L.; Nefedov, A.; Yang, C.; Heissler, S.; Wang, Y.; Wöll, C. Structural Evolution of $\alpha-\mathrm{Fe}_{2} \mathrm{O}_{3}(0001)$ Surfaces Under Reduction Conditions Monitored by Infrared Spectroscopy. Front. Chem. 2019, 7, 451.

(24) Sun, Y.-N.; Giordano, L.; Goniakowski, J.; Lewandowski, M.; Qin, Z.-H.; Noguera, C.; Shaikhutdinov, S.; Pacchioni, G.; Freund, H.-J. The Interplay between Structure and CO Oxidation Catalysis on Metal-Supported Ultrathin Oxide Films. Angew. Chem., Int. Ed. 2010, 49, 4418-4421.

(25) Liu, Y.; Yang, F.; Zhang, Y.; Xiao, J.; Yu, L.; Liu, Q.; Ning, Y.; Zhou, Z.; Chen, H.; Huang, W.; et al. Enhanced Oxidation Resistance of Active Nanostructures via Dynamic Size Effect. Nat. Commun. 2017, 8, 14459.

(26) Mirabella, F.; Zaki, E.; Ivars-Barceló, F.; Li, X.; Paier, J.; Sauer, J.; Shaikhutdinov, S.; Freund, H.-J. Cooperative Formation of LongRange Ordering in Water Ad-Layers on $\mathrm{Fe}_{3} \mathrm{O}_{4}(111)$ Surfaces. Angew. Chem., Int. Ed. 2018, 57 (5), 1409-1413.

(27) Davis, E. M.; Zhang, K.; Cui, Y.; Kuhlenbeck, H.; Shaikhutdinov, S.; Freund, H.-J. Growth of $\mathrm{Fe}_{3} \mathrm{O}_{4}(001)$ Thin Films on $\mathrm{Pt}(100)$ : Tuning Surface Termination with an Fe Buffer Layer. Surf. Sci. 2015, 636, 42-46.

(28) Merte, L. R.; Grabow, L. C.; Peng, G.; Knudsen, J.; Zeuthen, H.; Kudernatsch, W.; Porsgaard, S.; Lægsgaard, E.; Mavrikakis, M.; Besenbacher, F. Tip-Dependent Scanning Tunneling Microscopy Imaging of Ultrathin FeO Films on $\mathrm{Pt}(111)$. J. Phys. Chem. C 2011, 115 (5), 2089-2099.

(29) Genuzio, F.; Sala, A.; Schmidt, T.; Menzel, D.; Freund, H.-J. Interconversion of $\alpha-\mathrm{Fe}_{2} \mathrm{O}_{3}$ and $\mathrm{Fe}_{3} \mathrm{O}_{4}$ Thin Films: Mechanisms, Morphology, and Evidence for Unexpected Substrate Participation. J. Phys. Chem. C 2014, 118 (50), 29068-29076.

(30) Blöchl, P. E. Projector Augmented-Wave Method. Phys. Rev. B: Condens. Matter Mater. Phys. 1994, 50 (24), 17953-17979.

(31) Kresse, G.; Joubert, D. From Ultrasoft Pseudopotentials to the Projector Augmented-Wave Method. Phys. Rev. B: Condens. Matter Mater. Phys. 1999, 59 (3), 1758-1775.

(32) Kresse, G.; Furthmüller, J. Efficient Iterative Schemes for Ab Initio Total-Energy Calculations Using a Plane-Wave Basis Set. Phys. Rev. B: Condens. Matter Mater. Phys. 1996, 54 (16), 11169-11186.

(33) Perdew, J. P.; Burke, K.; Ernzerhof, M. Generalized Gradient Approximation Made Simple. Phys. Rev. Lett. 1996, 77 (18), 38653868.

(34) Li, X.; Paier, J. Partial Oxidation of Methanol on the $\mathrm{Fe}_{3} \mathrm{O}_{4}(111)$ Surface Studied by Density Functional Theory. J. Phys. Chem. C 2019, 123 (13), 8429-8438.

(35) Liu, Y.; Ning, Y.; Yu, L.; Zhou, Z.; Liu, Q.; Zhang, Y.; Chen, H.; Xiao, J.; Liu, P.; Yang, F.; et al. Structure and Electronic Properties of 
Interface-Confined Oxide Nanostructures. ACS Nano 2017, 11 (11), 11449.

(36) Zhang, W.; Li, Z.; Luo, Y.; Yang, J. First Principles Study on the Geometric and Electronic Structures of the $\mathrm{FeO} / \mathrm{Pt}(111)$ Surface. J. Phys. Chem. C 2009, 113 (19), 8302-8305.

(37) Giordano, L.; Pacchioni, G.; Goniakowski, J.; Nilius, N.; Rienks, E.; Freund, H.-J. Interplay between Structural, Magnetic, and Electronic Properties in a FeO/Pt(111) Ultrathin Film. Phys. Rev. B: Condens. Matter Mater. Phys. 2007, 76 (7), 75416.

(38) Spiridis, N.; Zając, M.; Piekarz, P.; Chumakov, A. I.; Freindl, K.; Goniakowski, J.; Kozioł-Rachwał, A.; Parliński, K.; Slęzak, M.; Ślęzak, T.; et al. Phonons in Ultrathin Oxide Films: 2D to 3D Transition in $\mathrm{FeO}$ on $\mathrm{Pt}(111)$. Phys. Rev. Lett. 2015, 115 (18), 186102.

(39) Condon, N. G.; Leibsle, F. M.; Parker, T.; Lennie, A. R.; Vaughan, D. J.; Thornton, G. Biphase Ordering on $\mathrm{Fe}_{3} \mathrm{O}_{4}(111)$. Phys. Rev. B: Condens. Matter Mater. Phys. 1997, 55 (23), 15885-15894.

(40) Spiridis, N.; Freindl, K.; Wojas, J.; Kwiatek, N.; Madej, E.; Wilgocka-Ślęzak, D.; Dróżdż, P.; Slęzak, T.; Korecki, J. Superstructures on Epitaxial $\mathrm{Fe}_{3} \mathrm{O}_{4}(111)$ Films: Biphase Formation versus the Degree of Reduction. J. Phys. Chem. C 2019, 123 (7), 4204-4216.

(41) Zaki, E.; Mirabella, F.; Ivars-Barceló, F.; Seifert, J.; Carey, S.; Shaikhutdinov, S.; Freund, H.-J.; Li, X.; Paier, J.; Sauer, J. Water Adsorption on the $\mathrm{Fe}_{3} \mathrm{O}_{4}(111)$ Surface: Dissociation and Network Formation. Phys. Chem. Chem. Phys. 2018, 20 (23), 15764-15774.

(42) Cutting, R. S.; Muryn, C. A.; Vaughan, D. J.; Thornton, G. Substrate-Termination and $\mathrm{H}_{2} \mathrm{O}$-Coverage Dependent Dissociation of $\mathrm{H}_{2} \mathrm{O}$ on $\mathrm{Fe}_{3} \mathrm{O}_{4}(111)$. Surf. Sci. 2008, 602 (6), 1155-1165.

(43) Rim, K. T.; Eom, D.; Chan, S.-W.; Flytzani-Stephanopoulos, M.; Flynn, G. W.; Wen, X.-D.; Batista, E. R. Scanning Tunneling Microscopy and Theoretical Study of Water Adsorption on $\mathrm{Fe}_{3} \mathrm{O}_{4}$ : Implications for Catalysis. J. Am. Chem. Soc. 2012, 134 (46), 1897918985.

(44) Zaki, E.; Jakub, Z.; Mirabella, F.; Parkinson, G. S.; Shaikhutdinov, S.; Freund, H.-J. Water Ordering on the Magnetite $\mathrm{Fe}_{3} \mathrm{O}_{4}$ Surfaces. J. Phys. Chem. Lett. 2019, 10 (10), 2487-2492.

(45) Yan, G.; Wähler, T.; Schuster, R.; Schwarz, M.; Hohner, C.; Werner, K.; Libuda, J.; Sautet, P. Water on Oxide Surfaces: A Triaqua Surface Coordination Complex on $\mathrm{Co}_{3} \mathrm{O}_{4}(111)$. J. Am. Chem. Soc. 2019, 141 (14), 5623-5627.

(46) He, Y. B.; Tilocca, A.; Dulub, O.; Selloni, A.; Diebold, U. Local Ordering and Electronic Signatures of Submonolayer Water on Anatase $\mathrm{TiO}_{2}(101)$. Nat. Mater. 2009, 8 (7), 585-589.

(47) Meier, M.; Hulva, J.; Jakub, Z.; Pavelec, J.; Setvin, M.; Bliem, R.; Schmid, M.; Diebold, U.; Franchini, C.; Parkinson, G. S. Water Agglomerates on $\mathrm{Fe}_{3} \mathrm{O}_{4}(001)$. Proc. Natl. Acad. Sci. U. S. A. 2018, 115 (25), E5642-E5650. 